\title{
Baton Rouge Brownfields Program in Old South Baton Rouge
}

\author{
T. L. Bunch, E. A. Miller, B. M. Hughes \& L. J. Lyons \\ City of Baton Rouge-Parish of East Baton Rouge, Louisiana, USA
}

\begin{abstract}
In 2000, the Baton Rouge Brownfields Program (BRBP) was created as a recommendation of the Horizon Plan, the City-Parish comprehensive plan. The Plan provides the framework for all City-Parish growth-oriented decisions and initiatives including Smart Growth, In-fill Development and Environmental Planning. Funding awarded through the United States Environmental Protection Agency (EPA) will target sites impacted by petroleum and hazardous substances in the Old South Baton Rouge (OSBR) area to support the revitalization efforts of the East Baton Rouge Parish Housing Authority (EBRPHA).

According to the 2000 Census, $24 \%$ of the OSBR population is unemployed, $32 \%$ live below the poverty level and $43 \%$ lack a high school diploma. Also, the median household income is three times below the national average, and less than $40 \%$ of the homes are owner-occupied.

The BRBP identified at least 28 properties in the OSBR area that had Underground Storage Tanks (USTs), indicating that at least 104 properties in this area may be affected. Environmental assessments and mitigation of potential risks will allow the EBRPHA to continue the efforts of their Housing and Urban Development (HUD) HOPE VI Program. EBRPHA efforts thus far include the demolition of a 95-unit and 76-unit public housing development and construction of 136 units in "traditional neighborhood" design.

Partnerships with organizations and community leaders are critical to redevelopment. These relationships are vital as OSBR continues to grow and strengthen.
\end{abstract}

Keywords: historical neighborhoods, infill development, smart growth, community revitalization, non-profit, mixed-use development, low-income communities, partnerships, sprawl. 


\section{Introduction}

The Baton Rouge Brownfields Program (BRBP), created as a recommendation of the Horizon Plan, began as a method to encourage redevelopment while addressing issues of Environmental Planning, Smart Growth, and In-Fill Development. Baton Rouge is addressing a range of issues typical of many southern U.S. cities including sprawl, automobile reliance, and development of environmentally-sensitive areas such as wetlands. Streets that are not pedestrianfriendly contribute to the city having some of the most dangerous streets in the state of Louisiana, according to the 2004 Surface Transportation Policy Project. Automobile dominance, combined with a lack of connectivity and transportation choices have resulted in increased instances of obesity in communities. Land developers often seek clean, cheaper greenfields instead of redevelopment in urbanized areas. Additionally, environmentally-sensitive areas such as wetlands become vulnerable to encroaching development. Patterns such as these discourage economic development and investment in the central city and have adverse effects on our public and environmental health.

Since the BRBP received a Brownfields Assessment Demonstration Pilot Grant in 2000 from the United States Environmental Protection Agency (USEPA), it has established a site inventory of 155 specific properties, been awarded more than $\$ 1.3$ million in assessment and cleanup funding, and conducted more than fifty (50) assessments for thirty-six (36) different sites. Additionally, it has leveraged almost $\$ 24$ million in redevelopment funding.

The BRBP is now targeting specific communities in the city. In 2005 and 2006 , the program received two (2) grants totaling $\$ 400,000$ from the USEPA for environmental assessments. This funding specifically targets petroleum and hazardous substance-impacted sites in the Old South Baton Rouge (OSBR) area to support the revitalization efforts of the East Baton Rouge Parish Housing Authority (EBRPHA).

\section{History of Old South Baton Rouge}

OSBR, established in the $1800 \mathrm{~s}$, is one of Baton Rouge's oldest subdivisions. The earliest settlement recorded is Magnolia Mound Plantation, created by James Hillins in 1786. The OSBR land area covers about three (3) square miles in the city of Baton Rouge. OSBR was home to some of the most popular restaurants in the city, as well as successful department stores, theaters, and grocery stores. A community once thriving from a number of social and civic organizations and rich business culture, OSBR has changed significantly over time. The change can be attributed to the exodus of both Whites and African-Americans from the area after the Civil Rights Movement in the 1950s and 1960s. Seeking greater opportunities, those with the financial means left areas like OSBR seeking better homes, jobs, and schools for their children. However, those who could not afford to leave remained in the community. With such a large out-migration of people, few businesses were able to remain successful. 
According to the 2000 United States Census, the Old South Baton Rouge area, located in Census Tract 21, has a 2,146 person population, with ninety-four percent (94\%) being African American and five percent (5\%) being White. Twenty-three and a half percent $(23.5 \%)$ of the population are unemployed, thirty-two and two-fifths (32.4\%) live below the poverty level, and forty-three percent $(43 \%)$ are high school dropouts. In addition, the median household income is three times below the national average, and less than forty percent $(40 \%)$ of the homes are owner-occupied. This Census Tract has been designated as a Difficult Development Area (DDA) by the United States Internal Revenue Service.

In addition to the historical significance of OSBR, the community is also located strategically in Baton Rouge. It is situated in close proximity to downtown Baton Rouge and Louisiana State University (LSU), the flagship university of Louisiana. Additionally, much of the community is parallel to the Mississippi River. The proximity to LSU and downtown Baton Rouge attracts some economic development interests, however, very few new businesses actually locate in the heart of OSBR

Currently, several areas in the community are in disrepair. Dilapidated properties host criminal activity and contribute to neighborhood blight. The physical appearance of these areas perpetuates the perception and fear of crime, which discourage investment in OSBR. The revitalization of the physical environment is a critical step in redeveloping the neighborhood.

\section{Redeveloping Old South Baton Rouge}

The Baton Rouge Brownfields Program was granted a total of $\$ 400,000$ by the USEPA for petroleum and hazardous environmental assessments. This funding is eligible to sites throughout East Baton Rouge Parish, however priority will be given to sites in the OSBR area to support the revitalization efforts of the East Baton Rouge Parish Housing Authority HOPE VI office. The EBPRHA is utilizing an \$18.6 million grant to demolish obsolete housing and purchase properties in the OSBR community for redevelopment.

The Baton Rouge Brownfields Program has identified at least twenty-eight (28) properties in the OSBR area that have had Underground Storage Tanks (USTs). Additionally, nineteen (19) of these sites have records indicating the USTs have been in place for more than twenty-five (25) years. Some of the oldest records suggest the USTs date back to the early 1950s. This information indicates that there are at least 104 properties in this area that may be potentially affected by these USTs. An environmental review of the project site revealed that historical past land uses more than likely contributed to the presence of these USTs. The contamination is most likely from petroleum-related products and services formerly located in the neighborhood.

\subsection{Targeted sites: BR113}

The BRBP has completed an assessment for the first target site, a former tire/auto repair shop, and was awarded cleanup funding. The USEPA granted 
$\$ 58,696$ to the EBRPHA for remediation activities involving petroleum contamination and asbestos containing materials. A Phase I Environmental Site Assessment identified environmental conditions including an UST, abandoned 55-gallon drums, hydrocarbon staining, and potential presence of lead-based paint and asbestos-containing materials. The Phase II assessment, which includes water and soil sampling, confirmed the presence of these environmental conditions.

The next step in the redevelopment process was to complete a Risk Evaluation/Corrective Action Program (RECAP) investigation. A RECAP determines the response to environmental contamination based on protection of human health and the environment, and sets minimum remediation standards for sites impacted by chemicals. The Louisiana Department of Environmental Quality (LDEQ) administers this program and oversees RECAP activities for the site. During this phase of assessments, six (6) USTs were discovered on the property. Initial site environmental review completed previously indicated that there were only two (2) USTs. The workplan created during the RECAP investigation addresses safely removing the USTs and methods to mitigate the impact of the other conditions. Additionally, brownfield sites such as BR113 can enroll in the Louisiana Voluntary Remediation Program (VRP), administered by the LDEQ. Property owners or potential owners who cleanup their sites under the guidelines indicated in the VRP can receive a release of liability and the same benefit flows to future owners of the property, Environmental assessments for this area and mitigation of potential risk will allow the EBRPHA to continue their efforts and leverage private investment in the area.

\subsubsection{Targeted sites: multiple sites}

In 2007, the BRBP funded environmental assessments for multiple sites in OSBR. These include approximately thirty (30) lots for redevelopment for the EBRPHA and other non-profit groups. These sites, in close proximity to BR113, will contain single-family residential homes and mixed-use developments. These lots are either on or adjacent to former heavy commercial sites including filling stations and auto repair shops.

A unique feature of these sites is that the Phase I and Phase II environmental assessments are conducted concurrently. Generally, the Phase I precedes the Phase II, however, site reconnaissance and environmental sampling and investigations will occur simultaneously due to time and access constraints. Critical to completing these assessments is coordinating a number of groups, including the USEPA, LDEQ, BRBP Steering Committee, the EBRPHA, the local community, and other non-profit groups. The BRBP facilitates meetings and active participation with these parties and will remain an integral partner throughout the redevelopment process.

\section{Long-term redevelopment strategy}

Essential to the redevelopment of OSBR are community involvement and establishing partnerships with various non-profit and civic organizations. While revitalization in OSBR is mostly a community initiative, there are various 
individuals and groups, public and private, which are catalyzing the redevelopment process. One such group is Plan Baton Rouge, a collaborative effort with EBRPHA Office of HOPE VI, the Center for Planning Excellence (CPEX), and the Baton Rouge Area Foundation (BRAF). Each of these non-profit organizations has a vested interest in OSBR and the BRBP has assisted them in conducting environmental site assessments in the area. Additionally, through these collaborations, the City-Parish is able to fulfill goals and objectives outlined in the Horizon Plan.

A major goal in the OSBR redevelopment strategy is to prevent displacing life-long residents. Private, expensive residential developments are appearing in some areas near the community. These developments have the potential to force out families and establishments that have been a part of the long history of OSBR. Low income levels and developer disinterest in affordable housing leaves very few choices for community members. However, the EBRPHA Office of HOPE VI is leading the effort to construct quality, affordable housing in OSBR. With an \$18.6 million grant from HUD, the EBRPHA is building single-family homes. The BRBP is assisting by coordinating the environmental investigations on targeted properties. Utilizing environmental assessment funding from the BRBP translates to more of the HUD funding used for redevelopment.

Ultimately, revitalization in any community is multi-party effort. The BRBP contributes not only financial resources, but also vision, knowledge, and expertise in Brownfields and redevelopment. Because the BRBP is administered by the Office of the Planning Commission, urban planners are able to provide a unique perspective on revitalization and economic redevelopment. The planners involved in the Brownfields Program introduce the planning process by facilitating redevelopment, organizing resources, and fulfilling goals outlined in the City of Baton Rouge Horizon Plan. Horizon Plan goals include the redevelopment of existing neighborhoods, affordable housing, and infill development. This community initiative has further catalyzed the redevelopment efforts in OSBR. The collaboration of organizations and community leaders has created a network of partnerships with each group contributing their own component to the shared vision of revitalization. These entities have combined to leverage funding from multiple sources, both public and private, that will improve the quality of life for residents of Old South Baton Rouge.

\section{References}

[1] Louisiana State University (LSU). LSU Office of University Relations, Baton Rouge, LA, http://www.lsu.edu/highlights/033/flower.html

[2] The Daily Reveille. "Waking Old South Baton Rouge," http://media.www.lsureveille.com/

[3] Mean Streets 2004, Surface Transportation Policy Project.

[4] United States Internal Revenue Service, 2008 IRS SECTION 42(d)(5)(C) QUALIFIED CENSUS TRACTS, http:/www.huduser.org/Datasets/qct/ qct2008m.PDF 